Association for Information Systems

AIS Electronic Library (AISeL)

Wirtschaftsinformatik 2021 Proceedings

Track 2: General Track - Innovative, emerging and interdisciplinary topics

\title{
Designing a Decision Support Tool to Improve the Recylability of Plastic Products
}

Tobias Prätori

Julius-Maximilians-Universität Würzburg

Norman Pytel

Julius-Maximilians-Universität Würzburg

Axel Winkelmann

Julius-Maximilians-Universität Würzburg

Follow this and additional works at: https://aisel.aisnet.org/wi2021

Prätori, Tobias; Pytel, Norman; and Winkelmann, Axel, "Designing a Decision Support Tool to Improve the Recylability of Plastic Products" (2021). Wirtschaftsinformatik 2021 Proceedings. 4.

https://aisel.aisnet.org/wi2021/YGeneralTrack/Track02/4

This material is brought to you by the Wirtschaftsinformatik at AIS Electronic Library (AISeL). It has been accepted for inclusion in Wirtschaftsinformatik 2021 Proceedings by an authorized administrator of AIS Electronic Library (AISeL). For more information, please contact elibrary@aisnet.org. 


\title{
Designing a Decision Support Tool to Improve the Recylability of Plastic Products
}

\author{
Tobias Prätori ${ }^{1}$, Norman Pytel ${ }^{1}$, and Axel Winkelmann ${ }^{1,}$ \\ ${ }^{1}$ University of Würzburg, Chair of Business Administration and Information Systems, \\ Würzburg, Germany \\ \{tobias.prätori, norman.pytel, axel.winkelmann\}@uni-wuerzburg.de
}

\begin{abstract}
The scarcity of resources means that recycling is becoming increasingly important to minimize environmental damage and to compete in the global marketplace. However, recycling rates are still relatively low, especially for plastic products. This is mainly because there is an information gap between the product design and end-of-life phases. We want to develop a decision support tool that provides the designers of plastic products with important information and supports design decisions based on ecological, but also economical and functional criteria. To achieve this, we apply a design science research approach and rely mainly on expert interviews results.
\end{abstract}

Keywords: Decision Support, Recycling, Plastics, Circular Economy, Product Design, Design Science Research

\section{Motivation}

Due to the scarcity of resources, both demand and competition for critical raw materials will continue to increase [1]. A possible strategy to solve this problem is a more efficient use of resources. The EU proposes a circular economy, which, in contrast to traditional linear models, does not assume that resources are abundant. Recycling in particular is an important pillar for closing the cycle [1,2]. Although plastics are omnipresent in our lives, plastic products' recycling potential, unlike metals, paper, or glass, has hardly been exploited [3]. The rates for landfill and thermal incineration of plastic waste are still high. This leads to a variety of negative effects for us and our environment, such as increased $\mathrm{CO} 2$ emissions or marine pollution $[3,4]$.

The product design phase is especially crucial in the context of the circular economy since the production processes and materials are defined in this stage [5]. These two factors significantly influence how easy it is to disassemble products into their components [2]. However, product developers often lack the specific knowledge that recyclers have $[6,7,8]$. To close this gap, we want to develop a digital decision support tool that provides designers of plastic products with important information about their recyclability. 


\section{Related Work}

In recent years, several technologies have become established that can enable CErelated decision support. Pagoropoulos et al. [9] identified three architectural layers in which digital technologies can be classified: Data collection, Data integration, and Data analysis. There are various scenarios in which technologies such as Radio Frequency Identification (RFID) and Internet of Things (IoT) are used to collect data to support CE. For example, RFID chips could be used to obtain complete information about the entire life cycle of products and thus enable a closed-loop supply chain [10, 11]. Furthermore, IoT sensors could be used to collect a variety of data on interconnected objects and machines for subsequent analysis [12, 13]. Breakthroughs in areas such as hardware and algorithms also open up promising new possibilities for data analysis [14]. In the past, for example, methods and tools from the field of artificial intelligence were used to promote $\mathrm{CE}$ through decision support $[12,15]$. Besides the collection and analysis of data, the integration of information plays an important role [13]. Data usually comes from heterogeneous sources, such as sensors, Enterprise Resource Planning (ERP), or Manufacturing Execution Systems.

Several authors developed tools to support decision making in the context of CE, with processes within the supply chain that can be tracked and evaluated. Mboli et al. [16] devolped a decision support system that uses a semantic ontological model to track, monitor and analyze products in real time with the focus on residual value and applied the model in a real-word use case to demonstrate its viability. Lechner and Reimannn [17] built on a case study and presented a non-linear optimization model to support decision-making in reverse logistics. Kinoshita et al. [18] proposed a decision support model of environmentally friendly and economical material strategy for life cycle cost and recyclable weight. The authors used a goal programming approach to solve the underlying multi-criteria decision problems and a case study to analyze environmental and economic aspects among procurement, assembly, and recycling.

In the past, several decision support tools were also introduced that directly address the recycling process. Irie and Yamada [19] introduced a decision support model to support product disassembly to recover material carbon. They extract the bill of materials and then use $0-1$ integer programming to determine if the material should be recycled or disposed of. Li et al. [20] performed a multi-criteria assessment of robotic disassembly. The developed decision support tool can compare the results from different recycling scenarios based on environmental, technological, and economical assessment criteria. Yu et al. [21] employed a fuzzy comprehensive evaluation and an analytic hierarchy process (AHP) approach to enable decision support for selecting an optimal method of recycling waste tire rubber. Paraskevas et al. [22] developed a Monte Carlo-based decision support tool to evaluate resource efficiency of secondary aluminium production. The tool identifies all feasible compositions of metal streams prior to remelting and quantifies the environmental effects.

Although some progress has been made in the past regarding decision support in the $\mathrm{CE}$ context, the low recycling rate of plastic products is still a problem that has not yet been adequately addressed. 


\section{Research Objective and Proposed Methodology}

Our research objective is to increase the recyclability of plastic products. We want to achieve this by providing product developers with a decision support tool to bridge the gap between design and end-of-life phase. In this context, we aim to investigate the following research question:

$$
\begin{aligned}
& R Q: \text { How should a decision support tool for the development of plastic } \\
& \text { products be designed? }
\end{aligned}
$$

To answer this research question, we intend to design the decision support tool as an IT artifact. We employ a design research approach, as proposed by Henver et al. [23]. The authors proposed a conceptual framework for executing and evaluating Information Systems (IS) research. Following Hevner et al. the research relevance is assured by addressing the needs from the environment and the rigor by drawing from the knowledge base. The environment consists of three main components: people, organizations, and technology [23, 24]. Our research involves multiple stakeholders within companies. In addition to the main stakeholders, the product developers or designers, other functions such as procurement, production, sales and related information systems are also affected. The stakeholder's demands are influenced by personal factors and organizational factors as well as by technological factors. The knowledge base contains foundations like theories methods as well as methodologies like data analysis techniques.

\section{$4 \quad$ Initial Results}

To define an initial list of requirements, we held several preliminary interviews with recycling and plastic industry experts. From this, we could already derive first requirements (see Table 1).

Table 1. Initial design features

\begin{tabular}{ll}
\hline No. & Feature \\
\hline 1 & Data export from enterprise systems \\
2 & Offer intuitive UI with high usability \\
3 & Calculation of relevant ecological, economic and functional measures \\
4 & Prioritization of the measures by the product developer \\
5 & Comparison of the alternatives based on the multiple criterias \\
6 & Feedback on product designs and suggestions for improvement \\
7 & Data import to enterprise systems \\
\hline
\end{tabular}

To ensure the tools's usability, it must be integrated into an existing IT infrastructure and into existing business processes. For example, it must be possible to export existing bills of material from ERP systems to use them in the tool. A user interface (UI) characterized by a high degree of usability serves to integrate the tool into routine operation. It must then be possible to use the results of the tool in other systems. Furthermore, the tool must be able to calculate various measures. In addition to 
ecological factors such as the $\mathrm{CO} 2$ index and recyclability, importance must also be attached to the product's functionality and cost-effectiveness. The developer must be able to prioritize these indicators so that the tool can show him the best alternatives according to his needs. In addition, the tool should be able to provide feedback to the designer on how to optimize the design with regard to its criteria.

The consideration of several factors results in a multi-criteria decision problem. To solve this complex problem, algorithms from the field of Multicriteria Decision Making (MCDM) are implemented. There is a variety of MCDM methods that differ in terms of required data, their mathematical properties, and other characteristics [25].To make a pre-selection for the actual implementation in the decision support tool, a preliminary literature analysis of MCDM methods was first carried out. Three criteria were considered: user-friendliness, data input and output, and potential application areas. Thus, we have identified three procedures that are considered for the actual implementation during further research: Technique for Order Preference by similarity to Ideal Solutions (TOPSIS) [26], Preference Ranking Organization METHod for Enrichment of Evaluations (PROMETHEE) [27] and Analytical Hierarchy Process (AHP) [28].

\section{$5 \quad$ Outlook and Contribution}

A literature analysis serves as a starting point for our further research. In this way, we want to conceptualize previous academic work in the context of decision support to enable ecological product design. To gain further practical insights into stakeholder demands, we conduct qualitative expert interviews. The experts are either directly product designers, decision-makers in companies that manufacture plastic products, act as consultants or multipliers in the plastic industry, or are know-how carriers in the recycling industry. Through these interviews, we want to gain insights into typical processes in plastics companies and get an overview of the typical IT system landscape within those companies. Since the design process is inherently iterative, the evaluation of the decision support tool will also be iterative [24]. For this purpose, the requirements are continuously compared with the implemented features and evaluated by the experts.

With the decision support tool we propose, it is possible to provide crucial ecological information already during the product development process. This makes it possible to design plastic products so that they can be more easily recycled. Furthermore, it is possible to transfer defined design principles to other use cases, making it possible to address a wide range of companies and industries. In this way, we can make an essential contribution to the implementation of a circular economy.

\section{Acknowledgements}

This work has been developed in the project DIMOP. DIMOP is part of the project ForCycle II which is funded by the Bavarian State Ministry of the Environment and Consumer Protection. The authors are responsible for the content of this publication. 


\section{References}

1. European Commission: A zero waste programme for Europe. Brussels (2014)

2. European Commission: Closing the loop - An EU action plan for the Circular Economy. Brussels (2015)

3. European Commission: A European strategy for plastics in a circular economy. Brussels (2018)

4. Ellen MacArthur Foundation: The new plastics economy (2016)

5. Mesa, J., González-Quiroga, A., Maury, H.: Developing an indicator for material selection based on durability and environmental footprint: A Circular Economy perspective. Resources, Conservation and Recycling. 160, 104887 (2020)

6. Poudelet, V., Chayer, J.-A., Margni, M., Pellerin, R., Samson, R.: A process-based approach to operationalize life cycle assessment through the development of an eco-design decisionsupport system. Journal of Cleaner Production. 33, 192-201 (2012)

7. Favi, C., Germani, M., Mandolini, M., Marconi, M.: Includes knowledge of dismantling centers in the early design phase: a knowledge-based design for disassembly approach. In: Proceedings of the 23rd CIRP Conference on Life Cycle Enineering, pp. 401-406 (2016)

8. Romli, A., Prickett, P., Setchi, R., Soe, S.: Integrated eco-design decision-making for sustainable product development. International Journal of Production Research. 53(2). 549$571(2015)$

9. Pagoropoulous, A., Pigosso, D. C. A., McAloone, T. C.: The Emergent Role of Digital Technologies in the Circular Economy: A Review. In: Proceedings of the $9^{\text {th }}$ CIRP IPSS Conference: Circular Perspectives on Product/Service-Systems, pp. 19-24 (2017)

10. Govindan, K., Soleimani, H., Kannan, D.: Reverse logistics and closed-loop supply chain: A comprehensive review to explore the future. European Journal of Operational Research. 240(3), 603-626 (2015)

11. Jayaraman, V., Ross, A. D., Agarwal, A.: Role of information technology and collaboration in reverse logistics supply chains. International Journal of Logistics: Research and Applications. 11(6), 409-425 (2008)

12. Reuter, M. A.: Digitalizing the circular economy. Metallurgical and Materials transactions B. 47(6), 3194-3220 (2016)

13. Salminen, V., Ruohamaa, H., Kantola, J.: Digitalization and big data supporting responsible business co-evoluation. In: Advances in Human Factors, Business Management, Training and Education, pp. 1055-1067 (2017)

14. Moreno, M., Charnley. F.: Can re-distributed manufacturing and digital intelligence enable a regenerative economy? An integrative literature review. In: International Conference on Sutainable Design and Manufacturing, pp. 563-575 (2016)

15. Rojek, I., Dostatni, E.: Machine learning methods for optimal compatibility of materials in ecodesign. Bulletin of the Polish Academy of Sciences: Technical Sciences. 68(2), 199-206 (2020)

16. Mboli, J. S., Thakker, D., Mishra, J. L.: An Internet of Things-enabled decision support system for circular economy business model. Software: Practice and Experience. 1-16 (2020)

17. Lechner, G., Reimann, M.: Integrated decision-making in reverse logistics: an optimization of interacting acquisition, grading and disposition processes. International Journal of Production Research. 1-20 (2019)

18. Kinoshita, Y., Yamada, T., Gupta, S. M., Ishigaki, A., Inoue, M.: Decision support model of environmentally friendly and economical material strategy for life cycle cost and recyclable weight. International Journal of Production Economics (244), 107545 (2020) 
19. Yamada, T., Irie, H.: Decision support model for economical material carbon recovery and reduction by connecting supplier and dissassembly part selections. Journal of Advanced Mechanical Design, Systems, and Manufacturing. 14(2), JAMDSM0024-JAMDSM0024 (2020)

20. Li, J., Barwood, M., Rahimifard, S.: A multi-criteria assessment of robotic disassembly to support recycling and recovery. Resources, Conservation and Recycling. 140, 158-165 (2019)

21. Yu, H., Chen, Y. C,; Zhang, L., Zhang, Z., Zhang, J., Miljkoviće, M., Oeser, M.: Decision support for selecting optimal method of recycling waste tire rubber into wax-based warm mix asphalt based on fuzzy comprehensive evaluation. Journal of Cleaner Production. 265, 121781 (2020)

22. Paraskevas, D., Ingarao, G., Deng, Y., Duflou, J. R., Pontikes, Y., Blanpain, B.: Evaluating the material source efficiency of secondary aluminium production: A Monte Carlo-based decision-support tool. Journal of Cleaner Production. 215, 488-496 (2019)

23. Hevner, A. R., Salvatore, T. M., Park, J., Ram, S.: Design science in information systems research. MIS quarterly. 28(1), 75-105 (2004)

24. Silver, M. S., Markus, M. L., Beath, C. M.: The information technology interaction model: A foundation for the MBA core course. MIS quarterly. 19(3), 361-390 (1995)

25. Zavadskas, E. K., Turskus, Z.: A Preference Ranking Organisation Method (The PROMETHEE Method for Multiple Criteria Decision-Making). Technological and Economic Development of Economy. 17(2), 397-427 (2011)

26. Hwang, C. L., Yoon, K.: Multiple Attribute Decision Making: Methods and Applications. Springer, New York (1981)

27. Brans, J. P., Vincke, P.: A Preference Ranking Organisation Method (The PROMETHEE Method for Multiple Criteria Decision-Making). Management Science. 31(6), 647-656 (1985)

28. Saaty, T. L.: Multicriteria decision making - the analytic hierarchy process. Planning, priority setting, resource allocation. RWS Publishing, Pittsburgh (1990) 